\title{
FACTORS INFLUENCING THE BUYING BEHAVIOUR OF MILLENNIALS TOWARDS INSURANCE PRODUCTS IN THE NIGERIAN INSURANCE MARKET
}

BAMGBOSE OLALEKAN SODIQ

\begin{abstract}
Investigating the factors affecting the purchase of insurance products and services among Millennials in Nigeria was the main purpose of the study. The study was guided by the following research objectives; exploring the methods millennials in Nigeria prefer in the accessing of insurance products and services; The assessment of the impact of the methods of promotion and messaging on the millennial population in Nigeria with regards to the uptake of insurance products and services and; to investigate the factors that influences the buying decision among the millennials in Nigeria; These where the major objectives of the study. It was ascertained that majority of the millennial age group in Nigeria, prefers to have a direct dealing with insurance company when buying insurance products and services. A further revelation shows that millennials, prefers the need of having insurance brokers/agents taking them through available options, regarding their choice of purchase. The study confirms that the prefer mode of information search among the millennial, is the television and radio with the social media following closely. With mobile payments confirmed as the most preferred modes of payment. The millennial prefers to purchase insurance products and services that was marketed on the social media and the internet, due to their preference of the internet over the traditional mainstream media. Mobile advertisements are becoming more popular among the Millennial population. With an increase in age and net income, direct dealing with insurance brokers and agents becomes more pronounced rather than peer referencing and the use of social media.
\end{abstract}

Keywords: Nigeria, Millennial. Millennial Population, Advertisement, Competitive market, Messaging, Social Media

JEL code: D01, D12, D15, D19, D40

\section{INTRODUCTION}

Akinlo (2012), defines insurance as the process through which individuals known as insurers accept the financial risk of another individual known as the insured for consideration in the form of premiums paid. Haufler (2013), argued that for a sustainable economic growth, a developed insurance industry is an essential catalyst. 
Insurance has its origins among the Chinese and Babylonian traders in the $3^{\text {rd }}$ and $2^{\text {nd }}$ millennia $B C$, respectively. To ensure that they did not lose their goods should a ship capsize, Chinese merchants would redistribute the goods among many vessels to limit the loss. The early Babylonian sailing merchants on the other hand developed a system where on receiving a loan to fund a shipment, the merchant would pay the lender an additional sum in exchange for the lender's guarantee to cancel the loan should the shipment be stolen or lost at sea (Vaughan, 1997).

Globally, the western European countries and the United states of America, dominate the world insurance markets (Global Fortune 500, 2015). In fact, 65\% world's insurance premium is accounted for among the Group of Seven (G7) countries (KPMG, 2014). Companies such as Berkshire Hathaway (Property/ casualty insurance) of USA, AXA (Life/health Insurance) of France and Allianz (Property/casualty insurance) of Germany leading in first, second and third place respectively (Global Fortune 500, 2015). In Africa, South Africa, Morocco, Nigeria and Egypt are the leading countries in gross insurance premiums with penetration rates of $14.28 \%, 2.97 \%, 0.68 \%$ and $0.68 \%$ respectively (KPMG, 2014).

Nigeria's insurance industry ranked fifth highest in Africa in terms of penetration after South Africa, Namibia, Kenya and Mauritius. The insurance industry in Nigeria consists of a number of players namely; 51 insurance companies (including foreign reinsurance companies' operating liaison offices in Nigeria) and 4 reinsurance companies, 460 registered insurance brokers and about 15,000 insurance agents (NIA digest, 2019). The ratio of the total annual gross insurance premium underwritten in a given year to the Gross Domestic Product (GDP), measures the insurance penetration for Africa as 3\% (A.I.O, 2019). This is relatively higher than the average emerging markets average of $2.65 \%$, but much lower than the advanced market of $8.07 \%$ and a global average of 6.13\% (Pricewaterhouse,2019). The uptake of insurance products in Nigeria is impacted by several factors. These include awareness, access, cost and complexity of the products. Additionally, buyer behaviour is influenced by socialisation, economic status, social status, age, gender, educational level and religion. When investigating the uptake of insurance products in the market in Nigeria, it is critical to reflect on the factors affecting the buying behaviour of certain age group towards insurance services.

Of interest to this study is the millennial age group generation, which includes those born between the year period of 1986 and 2000 (Strauss \& Howe 2000). Of the total population of Nigeria, this cohort makes up about $42.54 \%$ of the population (National Bureau of Statistics, 2019).

As a result of the emerging technologies, the millennial has emerged as a new kind of consumer that is discerning, well informed and pressed for time. They are looking for real-time access, faster and easier ways of transacting, clarity in product information and ease of payment. Recent events in the world economy have resulted in a drop in consumerism, with potential customers holding on to 
their money. They are now more careful with how they spend, have an increase propensity to shop around and negotiate deals (Parsons \& McLaren, 2011).

As consumers seek more meaningful associations from products and services, they are moving away from wanting value for money to wanting value for time (Parsons \& McLaren, 2011). Millennials are characterised by heavy digital media usage and a unique preference for smart phones. They are both experimental and experiential. They are quick to criticise and expect instant feedback. They are spending more time on the social spaces on the internet and increasingly, their work and play revolves around online platforms essentially; the internet is their first port of call for all things.

The millennial is global in nature and outlook. The market make-up is not only from different regions, nationalities and cultures, the product and service requirements have also taken a global character. The awareness to insurance among the millennial is now very much on the rise globally. The same options and standards of service is therefore expected from insurance providers (Ryan, 2014).

They exist in a time when consumer-driven marketing is increasingly important as customers seize control of the process and actively "pull" information helpful to them. Consumer-driven marketing activities included Internet reviews and word-of-mouth recommendations from friends and family, as well as in-store interactions and recollections of past experiences (McKinsey, 2009).

A modification of the consumer decision making process has also had an effect on the millennials' purchase behaviour. According to McKinsey (2009), the traditional decision making process of a consumer is depicted in funnel shaped model whereby consumers systematically narrow the initial-consideration set as they weigh options, make decisions, and buy products. Then, the post-sale phase becomes a trial period determining consumer loyalty to brands and the likelihood of buying their products again (McKinsey, 2009).

This is however changing. The contemporary consumer now moves back and forth between the stages depending on how much time they have and the quality of the references they are using. The resulting consumer purchase decision journey is circular (MacKinsey, 2009). Tapscott and Williams (2008) say technology has made the process more complex and dynamic and time starved consumers are demanding empowerment.

Li \& Bernoff (2011) make reference to an emerging phenomenon they call the groundswell- a social trend in which people use technologies to get the things they need from each other, rather than from traditional institutions like corporations. It is a result of people's desire to connect, new interactive technologies and online economies. Reference groups in the post-internet age no longer require face to face contact. They are now virtual communities involved in mass collaboration with a great influence on individual product choice. 


\section{STATEMENT OF THE PROBLEM}

Various studies have been undertaken to look at the insurance industry in Nigeria and its challenges. Gitau (2013), for example siting the strategies employed by insurance companies in Nigeria towards improving the low insurance penetration. while Odemba (2013), sited the factors influencing the purchase of life insurance products in Nigeria. Adeda (2014), also stated the problems faced by insurance companies in Nigeria towards building a competitive insurance market.

The results of the various research carried out gives a good insight into the area of insurance services purchase, but do not indicate if there is variation in uptake of insurance based on age demographics. The insurance industry in Nigeria, in addition, has targeted customers mostly on the basis of traditionally available products and services. These include the long term products (Annuities and life insurance) and the short term products (General and medical insurance which last for one year or less). Insurance companies have also focused on the purchasing power of the prospective customers. There is need to review this and begin segmenting the market, looking at demographically influenced buyer behaviour.

\section{REVIEW OF THE LITERATURE}

\section{Direct Channel of Insurance Sales}

Brophy (2013), defines direct channel as a process whereby insurance companies uses their own resources and capacity to distribute their products and services. Brophy (2013) points out how insurance companies have set up networks of branches that provide this direct service. A client in need of an insurance product or service walks into the company's premises and deals with the company's employees without any intermediation, hence direct channel. The insurance companies have also used their employees to seek out prospective clients especially by way of referral (Incentive Marketing Association, 2004). The employee represents the company and therefore in all respects, the company is viewed to be selling directly to the client.

\section{BROKERS AS A CHANNEL OF INSURANCE SALES}

Cummins \& Doherty (2006), define an insurance broker as "an individual or business firm, with some degree of independence from the insurer, which stands between the buyer and seller of insurance." They go ahead to indicate that intermediaries play a decisive role in facilitating the exchange between consumers and providers of financial services.

The Insurance Act, 2003, allows for the use of brokers in the sourcing of insurance and reinsurance business, in return for payment in the form of commissions. 
Allen \&Santomero, 2001; Freixas \& Rochet, 1997, traditionally argued that market imperfections, such as asymmetric information and transaction costs, are the reason for the need for brokers and financial intermediaries in financial services. With the emergence of new technologies and globalisation which in effect minimise the asymmetry and transactional costs, this argument is challenged. The fact that the demand for these intermediaries has even increased points to the existence of other factors other than market imperfections driving the demand for financial intermediation (Allen \& Santomero, 1998; Scholtens \& van Wensveen, 2000; Schmidt, Hackethal \& Thyrell (1999); Allen \& Gale, 1997).

\section{Agents as a Channel of insurance SAles}

According to the Insurance Act (2003), an agent is an individual who in consideration of a commission, solicits or procures insurance business for an insurer, a reinsurer or a broker. Sales people represent customers to the company championing their interests and managing the buyer- seller relationship (Kotler, 2000). Arulsuresh \& Rajamohan (2010), describe an agent as a primary source for procurement of insurance business. Customers also do not want to make a complicated decision on their own. (Mayer, 2008; Williams, 1999).

Agnihotri \& Rapp (2012), note that the above intermediaries will need to move their current skill sets to include data analysis and communicating via social media. They will also need to enhance knowledge of competition as competitive intelligence has emerged as a key tool to success in competitive environments. Kazemi Tame (2007), argues along the same lines indicating that the insurance industry extremely requires creativity, innovation, and entrepreneurship activities.

\section{BANCASSURANCE}

The process in which banks sells insurance products of its own insurance subsidiary, either through its own distribution channel or through outside agents is referred to as Bancassurance, Yuan (2011), Bancassurance has been traced back to France in 1980's with the development of the consumer and mortgage credit as well as the liberalisation of the financial markets (Artikis, Mutenga \& Staikouras; 2008).

In Nigeria, effective $1^{\text {st }}$ April, 2017, the National Insurance Commission (Naicom), issued operational guidelines on Bancassurance services. Banks in Nigeria are allowed to be involve in the marketing and selling of insurance products and services.

\section{Online Platforms}

The developments in communications and technology have changed distribution channels, allowing underwriters to bypass traditional intermediaries like insurance brokers Debling, (1998). 
Several research studies have been undertaken in regards to the use of online platforms in the marketing of products and services (De Valck, Van Bruggen \&Wierenga, 2009; Ohbyung \& Yixing, 2010; Trusov, Bucklin \& Pauwels, 2008; Van Den Bulte \& Wuyts, 2007). Steyn, Wallströ and Pitt (2010) however, point out that these studies have barely touched on financial services. However, Majtánová and Brokešová (2012), argued that the online social network sites (OSNSs), can be used for the marketing of financial services with a leaning to insurance. They indicate that even when insurance marketing has been considered online, it is discussed within the confines of websites of the insurance companies leaving Social media out.

These social sites serve to create online word-of-mouth marketing which for insurance companies would include Evangelist marketing, Community marketing, viral marketing and referral programs: (Farkas, Laurin \&Tomek, 2008). The platforms allow varied comments open for all to read. It has been scientifically proven that 50 per cent of these are positive and only 33 per cent are critical of the company or product (Jansen, Zhang, Sobel, \& Chowdury, 2009). Banan (2009), opined that social online platforms work better than the insurance companies' web sites which suffer low rates of repeat visits.

Insurance companies can utilise online platforms by creating applications or direct links to their home web sites allowing customers to purchase insurance policies, Majtanova \& Brokesova (2012). This could allow for improved trust with clients regarding the security of their personal information and provide an opportunity for interaction with professional employees during the purchasing of an insurance policy.

\section{Mobile Payment Platforms}

The mobile phone has now become an extension of most users' digital experiences. Where as in the past it was used primarily for communication, it now serves as a nerve centre for access to information and entertainment. The smart phone has further enhanced the user experience with applications and programs that have opened up a whole new world of possibilities (International Telecommunication Union, 2010).

Globally, more people now have mobile phones than have bank accounts. Morgan Stanley expects mobile internet usage to overtake desktop usage by 2015 (Meeker, 2010). Uptake of smartphones has increased dramatically with research indicating that the number of people with smartphones has leapt from $9 \%$ to $24 \%$ in the space of a year, and this is predicted to rise next year as cheaper devices become available (Mintel, 2011). 


\section{Promotion AND messaging - tARgeting}

\section{THE MILLENNIALS}

The earning potential of millennials makes them an important consumer group (Taylor \& Cosenza, 2002). This age group do greater percentage of the aggregate societal spending (Cui, Trent, Sullivan and Matinu, 2003; Krotz, 2005). Much of their interest is in the purchasing of jewelleries, clothes, sporting equipment, shoes, health and beauty kits, entertainment, and food (Barbagallo, 2003). The age or life-stage of this generation makes them unique to other age groups (Krotz, 2005). With a variety of electronic technology at their disposal, they are accustomed to instant global communication, material excess and media saturation (Barbagallo, 2003).

Selecting the appropriate medium in reaching the millennials is usually a challenge, due to the availability of a wide variety of media options (Hershatter \& Epstein, 2010; Kinley, Josiam and Lockett, 2010). Valentine and Powers (2013) found that millennials primarily used electronic media with television ranking first, the internet second, magazines third and radio fourth. The internet and television were rated high as a source of advertising information. Free community papers, in-store ads, Billboards, radio, direct mail, magazines, daily newspapers and weekly newspaper were rated low as a source of advertising information. Overall, traditional print media was rated lower than electronic media.

\section{CONSIDERATIONS FOR PURCHASE}

\section{NOvelty OF New BRANDS}

Curtin (2009) notes that millennials are inclined towards western culture in many ways, including in how they spend their money. They are highly adaptable to new brands and products, but generally not loyal to these brands thus earning themselves the tag of "brand switchers" (Xu, 2007; Noble, Haytko and Phillips, 2009; Olivier and Tanguy, 2008). It is important to note though that this does not in any way directly imply that millennials have reached their purchasing potential. This can only be expected to increase and grow with time (Juristic and Azevedo, 2011; Waters, 2006).

Millennials are not as brand-loyal or as driven by the same kind of brand label consciousness as the previous age cohorts (Wolfe, 2004). They have grown up in an era where shopping has become a form of entertainment with experiential aspects in a retail setting (Bakewell and Mitchell, 2003).

Gupta, Brantley and Jackson (2010) hold that millennials are attracted to distinctive brands through which they can self-express. They are also seen to carry a materialistic and consumer culture that is a result of technological innovation (Hanzaee and Aghasibeig, 2010). They openly express their concerns and feeling through various media (Hershatter and Epstein, 2010) and retailers are now alive to this facts, using the same media to gain feedback and insight from millennials, 
whom they have hitherto been unable to reach through conventional methods (Engel et al., 2011).

\section{ENVIRONMENTAL CONSCIOUSNESS}

Millennials have shown that they are environmentally conscious even in their purchase decisions (Henrichs, 2008). They are concerned about social responsibility and environmental issues (Barber, Taylor \& Dodd, 2009; Smith, 2012). They are supportive of social causes and socially responsible companies (Furlow, 2011). A majority are likely to trust socially responsible companies more and pay attention to their messaging, with resultant increase in purchase of their products (Millennial Case Study, 2006).

Some studies have found that millennials are the most environmentally conscious (Vermillion \& Peart, 2010). They favour socially and environmentally friendly brands (Spehar, 2006). Studies have also shown that educated consumers are increasingly worried about the long-term effects of products on their health, community, and environment (Spehar, 2006). However, according to Vermillion \& Peart (2010), consumers will not purchase a product only for its environmentally friendly attributes. A product must also contain an added benefit, such as safety, health, or cost efficiency.

\section{Customer Delight}

An emerging area of interest in consumer behaviour is customer delight. Whereas customer satisfaction is broadly characterised as a "post-purchase evaluation of product quality given pre-purchase expectation" (Kotler, 1991), customer delight is described as the act of surprising a customer by exceeding his or her expectations, which in turn creates a positive emotional reaction (Scott, 2004, and Seth, R. and Seth, K., 2005). It has also been shown that delighted customers had significantly high levels of willingness to pay, commitment loyalty, and repeat purchase (Barnes, Beauchamp, and Webster 2010). They are also more prone to sharing their experiences with others 62 per cent of the time (Swanson and Davis 2012). Beauchamp and Barnes (2015) identified employee affect, effort and skill as specific types of employee factors necessary to delight millennials.

\section{Peer Referencing}

Smith (2012) alludes to the fact that millennials use peers as a measure of merit of a product considering them to be more credible than traditional media or company sources of information. Li and Bernoff (2011) make reference to an emerging phenomenon they call the groundswell- a social trend in which people use technologies to get the things they need from each other, rather than from traditional institutions like corporations. They are increasingly successdriven, demonstrating their achievements through status products (Meister \& 
Willyerd, 2010). They will thus choose the brands that will help them construct and maintain this and other identities (Elliot \& Wattanasuwan, 1998). Parsons \& Maclaran (2011) find that brands provide numerous ways in which consumers can express themselves and with which to obtain the approval of peers, enabling them to make a social statement of who they are or who they would like to be.

Parsons \&Maclaran (2011), find that brands provide numerous ways in which consumers can express themselves and with which to obtain the approval of peers, enabling them to make a social statement of who they are or who they would like to be.

\section{PRICE}

Gauzente and Roy (2012), note that Millennials are price sensitive and take time to gathering and processing price-related information, including looking at non-price features. The first impression that millennials get, of a retailer's website for example, impacts their decision on whether to return. This is because, they form their judgements and opinions very quickly (Kim \& Fesenmaier, 2007; Lindgaard, Fernandes, Dudek \& Brown, 2006).

Eastman \& Liu (2012), found that millennials have higher levels of status consumption than Generation X or Baby Boomer consumers. Furthermore, Young and Hinesly (2012), emphasis that there should be further study undertaken to determine the motives that underlie millennials' behaviours.

\section{DATA COLLECTION METHODS}

The research made use of primary data which was collected using questionnaires, through stratified and simple random sampling techniques. The questionnaire included both open ended and closed-ended questions (Kothari, 2011). The questionnaires were administered through the help of research assistants to ensure reliability, clarification, accuracy and efficiency. Questionnaire enables data to be collected relatively quickly and also the researcher would not need to be present when the questionnaires were completed. This is useful for large populations when interviews would be impractical (Kosinski, Matz, Goling, Popov \& Stillwell 2015).

The questionnaire was divided into four sections. The first section sought for background information of the respondents while the subsequent sections addressed each of the research objectives. The questions were designed to collect both qualitative and quantitative data.

The questionnaire used questions designed to give the respondents alternatives that most closely corresponded to their position on the subject, and agreement scale questions based on a five-point scale with steps labelled Agree, strongly Agree, Disagree, Strongly Disagree and indifference. Questions were designed to ensure the relevance, logicality, simplicity and briefness of the questionnaire. 


\section{REGRESSION ANALYSIS}

A regression analysis was conducted due to the positive correlation that exist among the factors relating to the likelihood to buy. The dependent variable is the probability preference of buying as for the independent variable, online presence, customer service, brand loyalty, peer reference and price of the product were the main factors. The tables below show the regression analysis output:

Table 1

Model Summary

\begin{tabular}{|c|c|c|c|c|c|c|c|c|c|}
\hline \multirow[b]{2}{*}{ Model } & \multirow[b]{2}{*}{$\mathbf{R}$} & \multirow[b]{2}{*}{$\begin{array}{c}\mathbf{R} \\
\text { Square }\end{array}$} & \multirow[b]{2}{*}{$\begin{array}{l}\text { Adjusted R } \\
\text { Square }\end{array}$} & \multirow{2}{*}{$\begin{array}{l}\text { Std. Error } \\
\text { of the } \\
\text { Estimate }\end{array}$} & \multicolumn{5}{|c|}{ Change Statistics } \\
\hline & & & & & $\begin{array}{l}\text { R Square } \\
\text { Change }\end{array}$ & $\begin{array}{c}\text { F } \\
\text { Change }\end{array}$ & df1 & df 2 & $\begin{array}{l}\text { Sig. F } \\
\text { Change }\end{array}$ \\
\hline 1 & $.567^{\mathrm{a}}$ & .322 & .311 & 60939 & .322 & 29.817 & 5 & 314 & .000 \\
\hline
\end{tabular}

\section{Coefficients}

Table 2

\begin{tabular}{|c|c|c|c|c|c|}
\hline \multirow[b]{2}{*}{ Model } & \multicolumn{2}{|c|}{ Unstandardized Coefficients } & \multirow{2}{*}{$\begin{array}{c}\begin{array}{c}\text { Standardized } \\
\text { Coefficients }\end{array} \\
\text { Beta }\end{array}$} & \multirow[b]{2}{*}{$\mathbf{T}$} & \multirow[b]{2}{*}{ Sig. } \\
\hline & B & Std. Error & & & \\
\hline (Constant) & .946 & .159 & & 5.937 & .000 \\
\hline Online presence & .146 & .037 & .196 & 3.916 & .000 \\
\hline Brand loyalty & .291 & .044 & .324 & 6.553 & .000 \\
\hline \multicolumn{6}{|l|}{1} \\
\hline Peer reference & .143 & .041 & .178 & 3.491 & .001 \\
\hline Price & .017 & .045 & .023 & .383 & .702 \\
\hline Customer service & .102 & .035 & .170 & 2.873 & .004 \\
\hline
\end{tabular}

a. Dependent Variable: Likelihood to buy

The likelihood of an individual to buying insurance products based on online presence, customer service, brand loyalty, peer reference and price of the product makes the model fit for predicting. The model is fit to predict $32 \%$ of the likelihood to purchase based on the R Square value of 0.322 .

From the coefficient table above, price has no significant effect on the predictor (ability to purchase) hence, the need to drop it from the model.

$$
Y=\beta_{0}+\beta_{1} X_{1}+\beta_{2} X_{2}+\ldots .+\beta_{n} X_{n}+\varepsilon
$$

$\mathrm{X} 1=$ online presence

$\mathrm{X} 2$ = brand loyalty.

$\mathrm{X} 3=$ Peer reference

$\mathrm{X} 4=$ Customer service The regression model from Table 4.23 takes the form;

$\mathrm{Y}=.946+.146(\mathrm{X} 1)+.291(\mathrm{X} 2)+.143(\mathrm{X} 3)+.102(\mathrm{X} 4)$. 
If the four independent variables (online presence, brand loyalty, peer reference and customer service) are held constant, the value of probability to buy among millennials will be 0.946 according to the study. The regression coefficient of 0.146 and p-value of 0.000 , shows the positive relationship between the probability to buy and online presence. Holding other variables constant. An increase of a unit of online presence, where other variables are held constant, shows an increase of 0.146 in the likelihood to buy among millennials.

A positive relationship also exists between brand loyalty and likelihood to buy as shown by a regression coefficient of 0.291 and a p-value of 0.000 . This shows that likelihood of buying insurance services among millennials, increases with brand loyalty. The findings show that, holding all other variable constant a positive relationship exist between peer reference and likelihood to buying insurance services as shown by a regression coefficient of 0.143 and a p-value of 0.001 . This shows that a unit increase in peer reference would lead to a 0.143 increase in likelihood to buy insurance services among millennials. Holding all other variable constant, a positive relationship exists between customer service and likelihood to buy insurance services as shown by a regression coefficient of 0.102 and a $p$-value of 0.004 . This shows that a unit increase in customer service would lead to a 0.102 increase in likelihood to buying insurance services among millennials.

\section{DISCUSSION OF FINDINGS}

\section{Methods of Accessing Insurance Products}

From the research study it was established that $77.6 \%$ respondents prefer dealing with insurance offices personally when buying insurance products. Approximately $50 \%$ considers dealing with broker, agent or bank in purchasing insurance products. A further $34 \%$ of the respondents consider purchasing insurance products via alternative channels. Thus, agreeing with the imperfect market traditional thinking, such as asymmetric information and transaction costs.

Information search and options evaluation are pre-requisites needed in the purchasing decision making of a potential buyer of insurance services \{Allen and Santomero, 2001; Freixas and Rochet, 1997). The research study reveals that the millennials age group in Nigeria, even though they are digitally inclined and prefer to handle insurance product options evaluation and products information searches on their own, still feel the need to have an insurance specialist take them through the solutions available for them.

The millennial in satisfying their search for information on any products, prefers the use of television, radio and the social media as revealed by the research study. Thus, indicating a contradiction from preference of respondents on the internet over mainstream media. This is explained by the fact that television 
and radio are been viewed as passive sources of information while online sources are taken to be active sources. The preference for both TV and online sources among the millennial are supported by an increased online TV viewership among the age group. Valentine and Powers (2013), opined that millennials primarily used electronic media with television ranking first, the internet second, magazines third and radio fourth. Although, product information accessibility methods chosen amongst the millennials is not influenced by their gender, the educational level, income level and age of the respondents however have influence on the accessibility methods chosen. It appears that the higher the level of education and income level, the more likely for the millennial to prefer online access to information. Age though has the reverse effect on social media; as one gets older, the less likely their preference towards social media and the more likely preference to deal directly with the insurance company or interactions with an intermediary.

As online experience is fast becoming an extension of the day to day life of the millennial age group, thus indicating the importance it has on the purchase of insurance products among the group. Mobile, card and online payments, as an option of payment have direct/positive relationship with the Income and education levels among the millennial age group. The higher the level of education and income, the more likely respondents' preference to these alternative mode of payments options. Cash though remains the most preferred mode of payment.

The preference for non-cash modes confirms the fact that millennials are pressed for time. As they seek more meaningful associations from products and services, they are moving away from wanting value for money to wanting value for time (Parsons and Maclaran, 2011). The study also confirmed mobile payments as one of the preferred modes of payment. This confirms earlier studies that have indicated that we are able to carry out commerce by making payments through mobile phones which are now available in most places and have been enabled to carry out payment transactions. (Ballagas, Borchers, Rohs and Sheridan, 2006; Berg, Mörtberg and Jansson, 2005; Carton, Hedman, Damsgaard, Tan and McCarthy, 2012).

\section{PROMOTION AND MESSAgING OF INSURANCE PRODUCTS AND SERVICES}

The study indicated that a vast majority of millennials prefer the internet to traditional mainstream media and are more likely to buy a product if it was marketed on social media. They are also likely to buy a product if friends and other users said good things about it on social media and the internet. Additionally, they are on social media at least once a day, which makes it a very powerful tool for promotion and messaging. This agrees with Hershatter \& Epstein (2010) who observed that millennials access their content online using apps and on social media like Twitter and Facebook. 
The positive correlation between the likelihood to buy a product and the product's presence on the internet by way of advertising or feedback from friends and other users on their experience with a product, is an indicator that the internet has an influence on the purchase habits of millennials. This agrees with earlier findings that millennials are increasingly spending more time on the internet. Chaffey and Ellis-Chadwick (2012) have indicated how the bargaining power of a retail shopper is greatly increased when they are using the internet as they are able to evaluate products and compare prices.

The study further revealed that a majority of millennials are more likely to buy a product if it was marketed on social media and more likely to buy a product if friends and other users said good things about it on social media and the internet. This establishes the emergence of the internet and social media as prominent promotion and messaging platform of particular interest here is that the mobile phone has emerged as the preferred tool for internet access. Mintel (2011) indicated that the uptake of smartphones has increased dramatically with research indicating that the number of people with smartphones has leapt from $9 \%$ to $24 \%$ in the space of a year, and this is predicted to rise in coming years as cheaper devices become available. Availability of product information online and the ability to share experiences with networks empowers the millennial to make an informed decision, and feel that their information search and comparisons have been effective. This supports Tapscott and Williams (2008) assertion that technology has made the buying process more complex and dynamic and time starved consumers are demanding empowerment.

The study also confirmed findings of the study by InMobi (2012) indicating that millennials are getting more accustomed to mobile advertisements with a majority becoming as comfortable with mobile advertising as they are with TV or online advertising

\section{CONSIDERATIONS FOR PURCHASE OF INSURANCE PRODUCTS} AND SERVICES

A majority of the millennials show an inclination toward new brands, which agrees with previous studies that indicate that they are highly adaptable to new brands and products. These studies however also indicate that they are generally not loyal to these brands thus earning themselves the tag of "brand switchers" (Xu, 2007, Noble et al., 2009, Olivier and Tanguy, 2008). The study revealed on the contrary that they are loyal to the brands they choose which might be attributed to the Nigerian culture or to the ability or lack thereof to incur costs switching brands.

The green agenda seems to resonate well with the millennials with a majority preferring goods whose production has least impact on the environment, and that are produced using ethical means. Earlier studies have indicated the same outcomes (Henrichs, 2008; Barber, Taylor and Dodd, 2009; Smith, 2012). 
The study also revealed peer referencing as a strong consideration for purchase in the earlier years of a millennial's life. As they grow older, the less likely they are to find out about new products on their network on social media, or to choose products that help them make a statement. This would give an indication that peer referencing could be a useful communication tool for insurance companies, especially to the younger millennial market. The same effect with regard to advancement in age, is observed with increase in income. The more income the millennial makes, the less likely they are to refer to their peers for purchase decisions, and the less likely they are to make a statement through their purchases. With age also, the study revealed that they feel that they are getting value for money from their insurance services and are comfortable with the quality of service they receive. These trends are similar to the correlations found between individual characteristics specifically age and net income on, mode of accessing information about products and services, methods of accessing insurance and frequency of using promotional messaged on social media; with the increase in age and net income, individuals prefer to deal directly with the insurance agent and brokers rather than peers and social media.

Pricing and product standardisation came out as an issue of interest although it appears that the products available and their prices are not known to approximately a third of the millennial population. This indicates that there hasn't been enough effort put into first of all assessing the insurance needs of this particular age group and further, pricing the resultant products services at levels that are commensurate with their income levels.

With regards to customer service, half the population under study is satisfied with the service levels, feedback mechanisms and claims handling and repayment. The study showed a direct relationship between customer service and likelihood of the millennial to buy. As customers' service levels increase, so does the likelihood to buy.

\section{CONCLUSION}

\section{Methods of ACCESSING INSURANCE PRODUCtS}

The study established that direct access to the insurance company, and use of intermediaries like brokers and agents still remains the preferred method of accessing insurance products and services. It also revealed that banc assurance and other non-traditional intermediaries are emerging as likely alternatives for the millennials. Television and radio remain the preferred sources through which information is passively accessed. Active information searches though indicated that online sources are preferred. Cash payments remain the preferred payment mode with non-cash options gaining traction. The study therefore concludes that even though the traditional methods of access to information and payment remain strong, alternative methods are also gaining popularity especially with the millennial age group. 


\section{Promotion AND MESSAgING OF INSURANCE PRODUCTS AND SERVICES}

The internet and social media have emerged as strong platforms through which information on products and services is sourced. This is strengthened by the fact that the mobile phone is now ubiquitous and forms the primary mode of internet access by the millennials. The study concludes that the internet and social media are now a critical part of business promotion and messaging and must form an integral part of insurance companies' marketing endeavours.

\section{CONSIDERATIONS FOR PURCHASE OF INSURANCE PRODUCTS}

\section{AND SERVICES}

The study revealed that millennials are brand conscious and will be attracted to new brands and will be loyal to them. It also showed that the green agenda is gaining popularity with peer referencing, price and customer service being important considerations for millennials when they are making a purchase. The indication here is that the purchase activity for millennials is an experience that encompasses their emotions, world view and general status in society. It is important to them how a product of service feels, how it looks to others, its impact on the environment and the relations it provides for them with the provider of the product or service.

\section{RECOMMENDATIONS}

For further penetration of insurance services among the millennial in Nigeria. The following recommendations for improvement are implored:

\section{ACCESSIBILITY OF INSURANCE PRODUCTS}

In the contemporary business world, the Nigerian insurance companies must develop a broad eye- view of the customer, where the customers' needs and potential are known and are delivered to them back on their terms - in real time. A multi-intermediary approach to business should be developed by insurance companies allowing the potential customers the access to information and services through their preferred methods. They should in addition modernize their IT architecture across all lines of business to support this approach.

\section{COMMUNICATION OF INSURANCE PRODUCTS AND SERVICES}

The use of email, short messaging services (SMS), website, social media, and telemarketing, should be mostly used by insurance companies in passing information regarding their products and service to the millennial population. This will enhance easy assessments, review and interaction by customers. 


\section{CONSIDERATIONS FOR PURCHASE OF INSURANCE PRODUCTS AND SERVICES}

The emotional and the physical needs of the target population, should be considered by the Nigerian insurance companies when researching and developing products and services that meets their needs. experience service provision, gives a sustainable competitive advantage to whatever the insurance company.

\section{REFERENCES}

Anon (2009) The Consumer Decision Journey. McKinsey [Online]. Available: http:// www.mckinsey.com/insights/marketingsales/the_consumer_decision_journey.

Artikis, P. G., Mutenga, S., \& Staikouras, S. K. (2008). A practical approach to blend insurance in the banking network. The Journal of Risk Finance, Vol. 9, No. 2, pp. 106-124.

Bamasak, O. (2011). Exploring consumers' acceptance of mobile payments An empirical study. International Journal of Information Technology, Communications \& Convergence, 1(2), 173-185.

Chaffey, D., \& Ellis-Chadwick, F. (2012). Digital Marketing: Strategy, Implementation and Practice. Fifth Edition. Harlow, Pearson Education Limited

Chou, Y., Lee, C., \& Chung, J. (2004). Understanding m-commerce payment systems through the analytic hierarchy process. Journal of Business Research, 57(12), $1423-1430$.

Debling, F. (1998). Mail myopia: or examining financial services marketing from a brand commitment perspective. Marketing Intelligence and Planning, Vol. 16, No. 1, pp. 38-46.

Eastman, K. L., Eastman, J. K., and Eastman, A. D. (2002). Issues in marketing online insurance products: An exploratory look at agents' use, attitudes, and views of the impact of the Internet. Risk Management and Insurance Review, 2002, Vol. 5, No. 2, pp. 117-134. ISSN 1540-6296.

Gauzente, C., \& Roy, Y. (2012). Message content in keyword campaigns, click behaviour, and price consciousness: a study of Millennial consumers. Journal of Retailing and Consumer Services, 19(1), 78-87.

Hershatter, A., \& Epstein, M. (2010). Millennial and the world of work: an organization and management perspective. Journal of Business Psychology, Vol. 25, No. 2, pp. 211-223.

Juristic, B., \& Azevedo, A. (2011). Building customer-brand relationships in the mobile communications market: the role of brand tribalism and brand reputation, Brand Management, Vol. 18, No. 4/5, pp. 349-366. 